\title{
Adrenalin significantly increases intracranial pressure in hypovolemic cardiac arrest model in male piglets E Semenas* and L Wiklund
}

\author{
Address: Department of Surgical Sciences/Anaesthesiology and Intensive Care Medicine, University Hospital, Uppsala, Sweden \\ Email: E Semenas* - egidijus.semenas@gmail.com \\ * Corresponding author
}

from Scandinavian Update on Trauma, Resuscitation and Emergency Medicine 2009

Stavanger, Norway. $23-25$ April 2009

Published: 28 August 2009

Scandinavian Journal of Trauma, Resuscitation and Emergency Medicine 2009, 17(Suppl 3):O7 doi:10.1 186/1757-7241-17-S3-O7

This abstract is available from: http://www.sjtrem.com/content/I7/S3/O7

(c) 2009 Semenas and Wiklund; licensee BioMed Central Ltd.

\section{Introduction}

Resuscitation from hemorrhagic shock and subsequent cardiac arrest (CA) is a major clinical challenge in the care of trauma patients [1]. We hypothesized that adrenalin given during cardiopulmonary resuscitation (CPR) will improve cerebral perfusion response in hypovolemic cardiac arrest.

\section{Methods}

Twenty-one anesthetized male piglet (with a weight 24.3 $\pm 1.3 \mathrm{~kg}$ ) were bled $35 \%$ via femoral artery to a mean arterial blood pressure of $25 \mathrm{~mm} \mathrm{Hg}$ during $15 \mathrm{~min}$. Later piglets were subjected to 8 mins untreated ventricular fibrillation followed by $15 \mathrm{~min}$ open-chest CPR. At $9 \mathrm{~min}$ of CA piglets received amiodarone $1.0 \mathrm{mg} / \mathrm{kg}$ and hypertonic-hyperoncotic solution $4 \mathrm{ml} / \mathrm{kg}$ infusion for $20 \mathrm{~min}$ utes. At the same time vasopressin $0.4 \mathrm{U} / \mathrm{kg}$ was given intravenously to vasopressin group (VAS, $\mathrm{n}=9$ ), while adrenalin group received adrenalin $20 \mu \mathrm{g} / \mathrm{kg}$ (ADR, $\mathrm{n}=$ 12). Internal defibrillation was attempted from $11 \mathrm{~min}$ of $\mathrm{CA}$ to achieve restoration of spontaneous circulation (ROSC). Experiment was terminated at 3 hours after resuscitation.

\section{Results}

No significant differences were observed in resuscitability/ survival between the groups. There were no significant differences in cerebral cortical blood flow or protein S-100 $\beta$ levels after ROSC between the groups. Intracranial pressure was significantly higher in ADR group compared with
VAS group in the post resuscitation phase. Jugular bulb $\mathrm{pH}$ and base excess was higher in the ADR group $15(\mathrm{p}=$ 0.0003 and $p=0.0002$ ) and $30 \mathrm{~min}$ after ROSC in comparison with the VAS group $(\mathrm{p}=0.02$ and $\mathrm{p}=0.001)$. Besides, oxygen extraction in jugular bulb samples was greater in the VAS group compared with the ADR group at the same time points $(\mathrm{p}=0.03$ and $\mathrm{p}=0.003$, respectively).

\section{Conclusion}

Resuscitation with adrenalin significantly increased intracranial pressure though improvement of cerebral perfusion was reflected by higher jugular bulb $\mathrm{pH}$, base excess and lower oxygen extraction ratio with no significant changes in cerebral cortical blood flow.

\section{References}

I. Lockey D, Crewdson K, Davies G: Ann Emerg Med 2006, 48(3):240-4. 